\title{
Architecture of Protection \& Control System based on Energy Router
}

\author{
Q. P. WANG, Z. Q. BO, Z. F. FAN, X. LIU, Y. H.YI, S. M.GE, L.WANG \\ XJ Group, SGCC, Beijing, 100085, China
}

S. X. SHI

Tsinghua University, Beijing, 100081, China

\begin{abstract}
The Energy Router based on Solid State Transformer will be wildly used in future smart grid to meet requirements of huge distributed generation and bidirectional power flow. Based on principle study of Energy Internet \& Energy Router, this paper analyses the technical requirements of Protection \& Control $(\mathrm{P} \& \mathrm{C})$ for Energy Internet. According to gap analysis of current $\mathrm{P} \& \mathrm{C}$, the novel architecture of $\mathrm{P} \& \mathrm{C}$ based on Energy Router is presented and preliminary functional definition is proposed.
\end{abstract}

KEYWORD: Energy Router (ER); Protection \& Control (P\&C); Solid-State Transformer (SST)

\section{GENERAL INSTRUCTIONS}

In order to meet requirements of huge distributed generation and bidirectional power flow, Energy Internet has been direction of smart grid technology in the future. It has been the new global energy strategy that development and utilization of energy is based on electric power technology. Most of projected global energy needs can be satisfied by utilizing the green and renewable energy sources. To achieve this goal, renewable energy resources must be utilized on two fronts: large-scale centralized installations (such as wind or solar farms) and widescale DRERs. Energy Internet is presented by Jeremy Rifkin in his famous book - "The Third Industrial Revolution" [1].

Because the electric power is easy for collection, transmission and distribution, power grid is one of the best choices to realize Energy Internet. Power Energy Internet is defined as a power grid which can support bidirectional exchange by integration of distributed renewable generation, based on electronic and information technology.

The Energy Router based on Solid State Transformer will be wildly used in power transmission \& distribution network as key equipment for power energy exchange. It can support distributed generation and flexible transmission and distribution. But the existing control \& protection for current power grid are not suitable to Energy Internet anymore without concerning the transient of Energy Router.

Therefore it is quite important to research basic principle of protection \& control by taking Energy
Router into account. The control and protection is one of the most important parts of research area for Power Energy Internet as one of the five pillars of Energy Internet, which is based on information network, wide area measurement, high-speed sensor, high efficient calculation and intelligent control.

Based on principle study of Energy Internet, this paper analyses the technical requirement of protection \& control for Energy Internet. According to gap analysis of current $\mathrm{P} \& \mathrm{C}$, the novel architecture of $\mathrm{P} \& \mathrm{C}$ based on Energy Router is presented and preliminary functional definition is proposed.

\section{BASIC PRINCIPLE OF ENERGY INTERNET \& ENERGY ROUTER}

\subsection{Energy Interent}

The energy grid of the future will not appear to be very different from today's infrastructure [2]. Figure 1 shows this schematically - just like today.

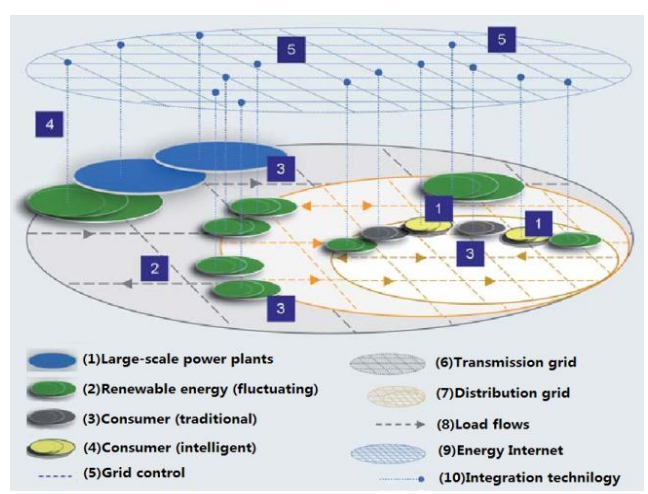

Figure 1. Infrastructure of future power grid - Energy Internet 
All individual components must be integrated (10) into a uniform communication infrastructure the Energy Internet (9), which will serve to map producers and consumers of the energy grid onto one virtual level.

CIMEG (Consortium for Intelligent Management of Electric-power Grid) advanced an anticipatory control paradigm named Local Area Grid [3].

\subsection{Energy router based on SST}

The concept of intelligent power routing (PR) is proposed as a new function in power delivery systems. The energy router is actually formed by an SST (Solid state transformer) device that performs control and voltage step-down function [3].

A single-phase SST circuit topology is illustrated in Figure 2. The SST is a power electronic device that does much more than just a voltage step-down function. The power frequency input signal of the primary side of the transformer turns into the high frequency signal. As the volume of the core type transformer is inversely proportional to frequency, so the volume of the SST is much smaller than the legacy transformer [4].

The SST can realize the control of power frequency, voltage and waveform. It can send messages to communicate with the same level SSTs through the optical fiber network. Besides, the SST can control the power flow real time; minimize the network loss; control voltage and reactive power optimization of the distribution system [5].

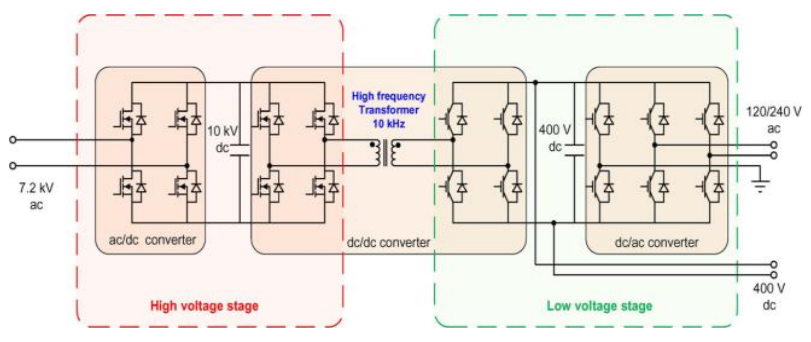

Figure.2 Single-phase SST circuit topology

The energy router support the functions can be categorized into the following seven domains: bulk generation, transmission, distribution, operation, market, customer, and service provider. Therefore the energy router is an enabling technological component in the energy internet operations.

\section{REQUIREMENT AND GAP ANALYSIS OF C\&P FOR ENERGY INTERNET}

\subsection{New requirements}

The existing control \& protection of power grid cannot meet the requirements of Energy Internet.

\subsubsection{Diverse ports for DERs and loads}

More and more distributed generators and DC loads are connected to distribution network. The different grid-connected ports including DC \& AC interface are necessary for different demands. Only AC port based on AC transformer is provided in traditional power grid. More types of ports can be provide to DC source and DC load by taking advantage of Solid-State Transformer. The current control system is definitely not suitable to the diverse gridconnected interface.

\subsubsection{Flexible power flow control}

The power flow control is very important to minimize loss or eliminate overload in distribution network. It is realized by switch operation to change network topology in current power grid, which cannot optimize system accurately and flexibly. But many power electronic devices can be used for active power control in energy internet, such as gridconnected inverter, SST and Unified Power Flow Controller (UPFC). The coordinative control of active power is one of the most important functional requirements for Energy Internet.

\subsubsection{Voltage and reactive power optimization}

The traditional solutions for eliminating voltage violation are tap changing of OLTC (On Load Tap Changer) and shunt capacitor switching. But there are other methods for precise voltage regulation in Energy Internet, for example SST, DSTATCOM and APF (Active Power Filter). The control algorithm of power electronic elements in Energy Internet for voltage regulation and reactive power optimization needs to be researched in $\mathrm{P} \& \mathrm{C}$ system.

\subsubsection{Custom power (high-quality power supply)}

In order to improve the quality of power supply, many devices are used in Energy Internet, which include DVR (Dynamic Voltage Regulator), APF, UPQC (Unified Power Quality Conditioner), etc. According to the demand of custom, different quality is guaranteed correspondingly. The control system of custom power is also one of the important issues of which needs to be solved in Energy Internet.

\subsubsection{Fault handling with distributed source}

There are different kinds of DGs and power electronic devices in Energy Internet. Therefore Fault handling in Energy Internet will be quite different to traditional distribution network. The Fault Location, Isolation and System Restoration (FLISR) should be developed for Energy Internet.

\subsubsection{Demand response with DGs}

Demand response is usually used for the balance of power generation and load. Only active loads are concerned in current distribution network instead of distributed generation in demand side. New functionality of demand response for Energy Internet 
should realize coordinative management of DGs and active loads.

\subsubsection{Real-time control for mass devices}

Most of DGs and power electronic devices in Energy Internet can be controlled for energy management. But in traditional distribution network, only switch and OLTC need to be controlled. The current distribution management system is composed by master station and remote terminals, and the coordinative control is realized by master station. It is impossible to implement the real-time control based on master station. The distributed real-time control is new requirement of Energy Internet.

\subsection{Status on P\&C for Energy Internet}

The control of the energy internet is inherently much more complicated than the traditional power distribution system. The multi layers control system in the FREEDM (Future Renewable Electric Energy Delivery \& Management) system is classified [6][7]. These controls are further classified into two groups: IEM (Intelligent energy management) control and IFM (Intelligent fault management) control. This architecture allows the FREEDM system to be scalable and the number of IEM \& IFM nodes can be increased or decreased without any major change to the operating system[8].

\subsection{Gap analysis of $P \& C$ for Energy Internet}

1) The concentrated architecture of control \& protection cannot support real-time control and management of massive DGs and active loads.

2) The current distribution network is not suitable for massive DGs connection.

3) The existing protection cannot realize fault detection \& isolation in AC/DC hybrid network.

4) The control system is only suitable for traditional distribution network and cannot control new power electronic devices.

5) The master station for traditional distribution network cannot implement coordinative control of distributed real-time control.

\section{ARCHITECTURE OF P\&C BASED ON ER}

\subsection{Architecture of P\&C based on Energy Router}

The architecture of traditional Distribution Automation (DA) system is not suitable to Energy Internet in the future anymore. The new architecture for Energy Internet needs to be researched to support real-time control and management of massive DGs and active loads.

The architecture of $\mathrm{P} \& \mathrm{C}$ system for Energy Internet should be divided into different levels, shown in Figure 3. The basic level is composed by sensors, meters and measuring devices for measurement and control, which are combined with energy routers or power electronic devices. Intelligent Terminal Unit (ITU) is the local control unit for coordinative control with other ITUs, which can be configured by master station and control energy routers and power electronic devices. The wide-area control and energy management system is used for optimization of power grid and configuration of local ITUs, which is installed in master station.

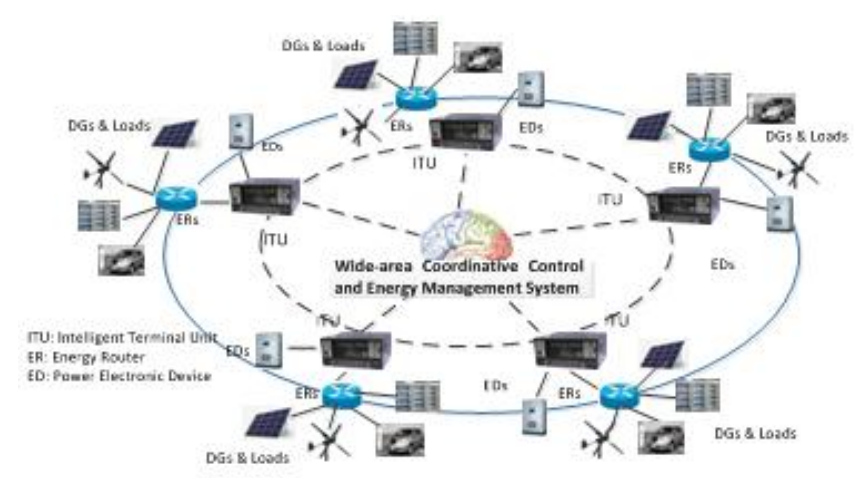

Figure.3 Architecture of P\&C system for Energy Internet

Communication network is the important part of $\mathrm{P} \& \mathrm{C}$ of Energy Internet. Communication protocols already exist worldwide for individual sections of integrated communication. These protocols are mainly limited to one section, meaning that an integrated communication system is still a long way off. A key task to the drive towards realizing the Energy Internet will be the need to establish an integrated, bi-directional communication system from generation to the end consumer.

Furthermore, the importance of virtual power plants will continue to grow, and these will be dependent on up-to-date data. If an integrated communication system exists, new products and services can be developed. The communication system must also be available for new products. The communication standards must be open to enable other applications to be integrated.

\subsection{Function definition for novel P\&C}

\subsubsection{Real-time control of ER with diverse ports}

The energy router provides different type of ports for different voltage level AC/DC source and AC/DC load. The interface of energy router based on SST is shown in Figure 4.

The energy router based on SST has 4 kinds of voltage ports: low-voltage AC, low-voltage DC, mid-voltage AC and mid-voltage DC. The lowvoltage ac and dc ports are used to connect DGs and loads. Some DC loads and DGs with DC output (such as PV and battery) can be connected to energy router directly, and other DGs with AC output (such as micro-gas turbine and wind turbine) can be connected to DC bus by AC/DC converter. The mid- 
voltage $\mathrm{AC}$ port is connected into the three-phase power distribution line. It can also be connected to other energy routers by mid-voltage DC port. The real-time control is expected to support the diverse ports of energy router. It is also the basis of the coordinative control and autonomous management for multi energy routers.

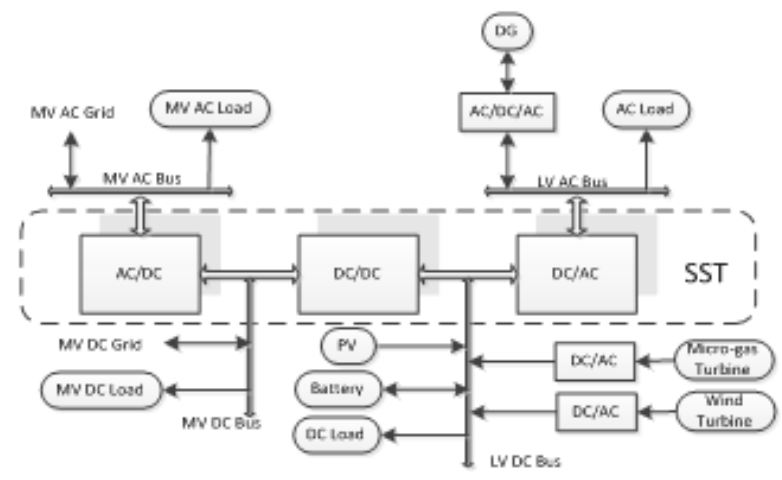

Figure.4 Energy router with diverse ports

\subsubsection{Autonomous management based on multi-agent}

The nodes of Energy Internet are sub-grid of distribution network. Each of them should be autonomous to realize distributed control and management. Based on multi-agent technology, ITU can implement fast network analysis and real-time control by communication with corresponding ITUs. The configurations of local control are set by master station.

\begin{tabular}{|c|c|c|c|c|}
\hline $\begin{array}{c}\text { Loss } \\
\text { Minimization }\end{array}$ & $\begin{array}{c}\text { Voltage } \\
\text { Regulation }\end{array}$ & Custom Power & $\begin{array}{c}\text { Demand Response } \\
\text { with DG }\end{array}$ & $\begin{array}{c}\text { Dynamic } \\
\text { Rating }\end{array}$ \\
\hline $\begin{array}{c}\text { Power Flow } \\
\text { Optimization }\end{array}$ & $\begin{array}{c}\text { Reactive } \\
\text { Power Control }\end{array}$ & $\begin{array}{c}\text { Power Quality } \\
\text { Optimization }\end{array}$ & $\begin{array}{c}\text { Load \& DG } \\
\text { Forecast }\end{array}$ & $\begin{array}{c}\text { State } \\
\text { Monitoring }\end{array}$ \\
\hline $\begin{array}{c}\text { Distributed Power Flow } \\
\text { Calculation \& State Estimation }\end{array}$ & $\begin{array}{c}\text { Local Dynamic Topology } \\
\text { Analysis }\end{array}$ & $\begin{array}{c}\text { Communication with } \\
\text { other ITUS }\end{array}$ \\
\hline \multicolumn{5}{|c|}{ Local SCADA } \\
\hline
\end{tabular}

Figure.5 Coordinative control and autonomous management

The functionalities of coordinative control and autonomous management are shown in Figure 5.

\subsubsection{Protection and FLISR for Power Energy Internet}

The typical protection and feeder automation for current distribution network are developed without concerning distribution power source in consumer side. The DGs and power electronic devices will influence protection and fault location greatly. It is necessary to research new algorithm of fault location for Energy Internet.

Many new power electronic technologies can be used to implement fault isolation and service restoration. SFCL (Superconducting Fault Current Limiter) can limit short current when fault occurs. The SST and grid-connected inverter can isolate fault feeder or limit short current. SSTS (Solid-state Transfer Switch) can switch load to other power source within $10 \mathrm{~ms}$ to restore power supply.

\subsubsection{Wide-area control and energy management}

The network analysis and optimization are mainly implemented by master station in current distribution network. The distributed analysis and real-time control are executed by ITUs instead of master station because of the huge amount of information and the real-time requirement.

The wide-area coordinative control and energy management system in master station is a brain of Energy Internet, which can set control logic and configuration to ITUs according network analysis results. Based on coordinative configuration, ITUs can work individually without master station.

\section{CONCLUSIONS}

The novel architecture of Protection \& Control based on Energy Router is presented firstly in this paper. It can meet the requirements of Energy Internet and Energy Router. Based on new architecture, the basic functionalities are defined, including real-time control of energy router with diverse ports, autonomous management based on distributed multiagent, protection \& FLISR for Power Energy Internet and wide-area coordinative control and energy management. It can be used to support the development of Energy Internet.

\section{ACKNOWLEDGEMENTS}

The research work was supported by Science \& Technology Project of SGCC under Grant No. 61065009.

\section{REFERENCES}

[1] Jeremy Rifkin. The Third Industrial Revolution. Washington: AEI Press, 2011, 9.

[2] Orestis Terzidis. Internet of Energy: ICT for Energy Markets of the Future. Berlin: Industrie-Förderung Gesellschaft mbH, 2010,2.

[3] Tsoukalas, L.H.; Gao, R., From smart grids to an energy internet: Assumptions, architectures and requirements, DRPT 2008. Third International Conference, vol., no., pp. 94, 98, 6-9 April 2008

[4] LING Chen, GE Baoming. Research on power electronic transformer in distribution network. Power system protection and control, 2012, 40 (2): 34-39

[5] Nguyen. Smart Power Router: A Flexible Agent-Based Converter Interface in Active Distribution Networks. IEEE Transactions on Power System, 2011, 2, 487-495.

[6] Huang, A. Q. The Future Renewable Electric Energy Delivery and Management System. Proceedings of the IEEE, vol. 99, no.1, pp.133,148, Jan. 2011

[7] WANG Chengshan, YUXuyang. Distributed coordinative emergency control based on multi-agent system. Power System Technology, 2004, 28 (3): 1-5

[8] YANG Xusheng. Study on multi-agent architecture based decision support system for power system. Automation of Electric Power Systems, 2002, 26 (18): 45-49 